\title{
eHealth and mHealth
}

\author{
Robert John Moss, ${ }^{1}$ András Süle, ${ }^{2}$ Stephanie Kohl ${ }^{3}$
}

${ }^{1}$ Scheldezoom Pharmacy, 's Gravenpolder, The Netherlands ${ }^{2}$ Department of Pharmacy, Péterfy Hospital - National Institute of Traumatology, Budapest, Hungary ${ }^{3}$ Policy and Advocacy, European Association of Hospital Pharmacists, Brussels, Belgium

\section{Correspondence to} Stephanie Kohl, Policy and Advocacy, European Association of Hospital Pharmacists, Brussels, 1200, Belgium; Stephanie.Kohl@ eahp.eu

Published Online First

Check for updates

(C) European Association of Hospital Pharmacists 2019. No commercial re-use. See rights and permissions. Published by BMJ.

To cite: Moss RJ, Süle A Kohl S. Eur J Hosp Pharm 2019:26:57-58.

\section{ABSTRACT}

Both electronic health (eHealth) and mobile health (mHealth) are becoming prominent components of healthcare. In order for healthcare electronic services to be safe and effective and add genuine value to the system, the European Association of Hospital Pharmacists (EAHP) believes that these should be developed in close collaboration with healthcare professionals including hospital pharmacists, and patients. Consequently, the EAHP calls in its position paper upon national governments and health systems across Europe to work towards (1) systematic and European Union-wide achievement of electronic prescribing, administration and use of electronic medical records; (2) ensuring barcoding of medicines to the single units in primary packages to enable more widespread take-up of bedside scanning in European hospitals, thus improving patient safety; (3) appropriate regulatory oversight mechanisms for mHealth applications to ensure that they have a positive impact and adequately protect patient data; (4) provision of appropriate eHealth/mHealth training opportunities to healthcare professionals and promotion of digital health literacy; and (5) involvement of hospital pharmacists in the design, specification of parameters and evaluation of information and communication technology within the medicines processes.

Revision of the position paper approved by the EAHP General Assembly, June 2017.

The position paper sets out the position of the European Association of Hospital Pharmacists (EAHP) on eHealth and mHealth.

$e H e a l t h$, or electronic health, refers to healthcare services provided with the support of information and communication technology (ICT)—such as computers, mobile phones and satellite communications-for health services and information.

mHealth, or mobile health, refers to the use of smart or portable devices for health services and information.

eHealth/mHealth encompasses a vast spectrum of healthcare services, ranging from electronic prescribing and medical records to text message prompts to remind patients to take their medicines. eHealth and mHealth are thus becoming prominent components of healthcare. In order for healthcare electronic services to be safe and effective and add genuine value to the system, the EAHP believes that these should be developed in close collaboration with healthcare professionals including hospital pharmacists, and patients.

Consequently, EAHP's member associations call on national governments and health systems across Europe to work towards the following:

- Systematic andEU-wide achievement of electronic prescribing, administration and use of electronic medical records (EMR).
- Ensuring barcoding of medicines to the single units in primary packages to enable more widespread take-up of bedside scanning in European hospitals, thus improving patient safety.

- Appropriate regulatory oversight mechanisms for mHealth applications to ensure that they have a positive impact and adequately protect patient data.

- Provision of appropriate eHealth/mHealth training opportunities to healthcare professionals and promotion of digital health literacy.

- Involvement of hospital pharmacists in the design, specification of parameters and evaluation of ICT within the medicines processes.

\section{THE NEED TO ACHIEVE UNIVERSAL USE OF ELECTRONIC PRESCRIBING, ADMINISTRATION AND EMRS}

A key goal for the eHealth agenda in Europe should be the systematic and EU-wide achievement of electronic prescribing, administration and use of EMRs. Both developments offer significant opportunity for improving safety, quality and efficiency in the delivery of patient care, particularly, but not exclusively, in relation to their role in preventing medication errors and improving interface management of patient care. The importance of the protection of patient data needs to be one of the key considerations, wherefore stringent data protection rules must be adhered to.

The European Commission in its 2012-2020 eHealth Action Plan ${ }^{1}$ highlights the importance of interoperability of eHealth services. Consequently, in moving towards a digital single market, the European Commission seeks to adopt the new European Interoperability Framework by 2020, which also supports the interoperability of health services. The EAHP supports this ambitious goal.

\section{THE USE OF BARCODE SCANNING TECHNOLOGY TO PROMOTE PATIENT SAFETY IN HOSPITAL THROUGH BEDSIDE SCANNING}

As a key patient safety requirement, the EAHP has for years advocated the need to introduce barcoding of medicines to the single unit primary package at the manufacturing stage. This public call is made to enable more widespread implementation of bedside scan checks immediately prior to administration of a medicine to a patient in hospital. The scan allows an assurance to take place that the medicine which is to be given is indeed the right medicine for the right patient, being administered by the right route and being given at the right time. Studies indicate such practice can reduce medication error by over $40 \% .^{2}$

Implementing electronic prescribing, together with bedside scanning, will complete the patient 
safety cycle, and also promotes accurate electronic patient record keeping. For these reasons the European Commission, national governments, health system managers, manufacturing, packaging and software industries should understand the link between electronic prescribing, EMRs and bedside scanning, and their importance in improving patient safety.

Positive examples are available in this regard from hospitals in Belgium, ${ }^{3}$ Switzerland ${ }^{4}$ and the USA. ${ }^{5}$ The achievement of bedside scanning of medicines across Europe should be understood as an important eHealth goal of strong patient safety value to be achieved in the years ahead. The use of barcoding at the primary package level could be beneficial for hospitals, and has the potential to enhance patient safety in care institutions and at home by allowing care patients or caregivers to scan medication just prior to administration.

\section{THE OPPORTUNITIES FROM MHEALTH FOR IMPROVING PATIENT EMPOWERMENT AND SELF-MANAGEMENT}

Mobile technologies such as smartphones, tablets, watches, glasses and other wearable devices are increasingly used by patients, ${ }^{6}$ also for health-related purposes. Undoubtedly many potential opportunities exist from both current applications and future applications in relation to such areas as improving individual patient understanding and self-management in relation to prescribed treatments. The advances made in the mHealth and eHealth sector could also contribute to the enhancement of the efficiency of healthcare provision by using data produced outside the direct healthcare system.

However, care and vigilance must also be taken in relation to potential 'rogue' or unregulated applications, which have not received appropriate oversight in their construction and have the potential negative impact of offering contradictory, inaccurate or low-quality advise to patients.

The EAHP perceives a level of regulatory oversight may be required in the future development of such applications, potentially through kitemark or national approval schemes in the first instance. Part of the evaluation should address the transparency, safety, reliability and interoperability of applications. A specific focus should be put on application with a high risk. Of particular importance is the need to protect the privacy of patient data, especially in regard to the commercial use of data, which calls for the identification of ethical solutions for storing and monitoring patient data. Patients need to be informed in case data gathered by an application are accessed and processed and of the purpose of such use.

The appropriate level of regulatory oversight of mHealth applications needs to be determined. Thus, the EAHP welcomes the adoption of the Code of Conduct on privacy for mHealth applications ${ }^{7}$ which should be adhered to by app developers and the rules contained within the Medical Devices Regulation. ${ }^{8}$ The latter provides for an assessment by the notified body of apps embedded or installed in a medical device, or apps used for performing for therapeutic or diagnostic purposes.

Moreover, the EAHP calls on the 2014-2019 eHealth workstreams of the European Commission which should continue to duly consider the appropriate level of regulatory oversight of mHealth applications.

The unique role of hospital pharmacists in advising on medicines use provides the opportunity to function as a bridge between medicines and technology. Their knowledge and direct access to patients should be used in both the development of new mobile applications and educating patients about their use.

\section{PROVISION OF APPROPRIATE EHEALTH/MHEALTH TRAINING OPPORTUNITIES TO HEALTHCARE PROFESSIONALS}

eHealth and mHealth technologies are advancing at a rapid pace, often outpacing both regulatory systems with healthcare systems and health professional education and training programmes. There is therefore a need for governments and health systems to give adequate support to health professionals in keeping both their competencies in the area of eHealth/mHealth up to date. A specific focus should be put on the promotion of digital health literacy. The implementation of new technological innovations and processes within health systems must also be conducted with healthcare professional training needs significantly in scope.

\section{THE NEED TO INVOLVE HOSPITAL PHARMACISTS IN HOSPITAL ICT DESIGN AND SPECIFICATION}

The European Statements of Hospital Pharmacy ${ }^{9}$ include in section 1.7 a clear call to health system managers that 'Hospital pharmacists must be involved in the design, specification of parameters and evaluation of ICT within the medicines processes. This will ensure that pharmacy services are integrated within the general Information and Communication Technology (ICT) framework of the hospital including electronic health (eHealth) and mobile health (mHealth) procedures'. This position paper re-emphasises that call, and reiterates the support it has received from the hospital pharmacy profession and other healthcare professionals and patient interest.

Collaborators Delegates of the 47th EAHP General Assembly.

Competing interests None declared.

Patient consent Not required.

Provenance and peer review Commissioned; internally peer reviewed.

Author note The position paper was approved and adopted by the delegates of the 47th EAHP General Assembly.

\section{REFERENCES}

1 Communication from the Commission to the European Parliament, the Council. The European Economic and Social Committee and the Committee of the Regions, eHealth Action Plan 2012-2020 - Innovative healthcare for the 21st century, COM(2012) 736 final. 2012.

2 Poon EG, Keohane CA, Yoon CS, et al. Effect of bar-code technology on the safety of medication administration. N Engl J Med 2010;362:1698-707.

3 De Rijdt T. Computerised physician order entry and bedside scanning as a tool to improve patient safety. European Journal of Hospital Pharmacy 2012;19:320-1

4 Bonnabry P. Vision from a hospital pharmacist on bar coding of pharmaceuticals, at the GS1 Healthcare Conference. Prague, Czech Republic, 2011.

5 Helmons PJ, Wargel LN, Daniels CE. Effect of bar-code-assisted medication administration on medication administration errors and accuracy in multiple patient care areas. Am J Health Syst Pharm 2009;66:1202-10.

6 IMS Institute for Healthcare Informatics. Patient adoption of mHealth - use, evidence and remaining barriers to mainstream acceptance: IMS Institute for Healthcare Informatics, 2015.

7 Data Protection Working Party. Final draft of the Code of Conduct on privacy for mHealth apps. 2016.

8 EUR-Lex. Regulation of the European Parliament and of the Council on medical devices and amending Directive 2001/83/EC, Regulation (EC) No 178/2002 and Regulation (EC) No 1223/2009. 2017.

9 The European Statements of Hospital Pharmacy. Eur J Hosp Pharm 2014;21:256-8. 